\title{
Contextuality and Co-Creation Matter: A Qualitative Case Study Comparison of Living Lab Concepts in Urban Research
}

\author{
Yvonne Franz, Karin Tausz, and Sarah-Kristin Thiel
}

\author{
"My greatest challenge has been to change") \\ the mindset of people. Mindsets play \\ strange tricks on us. We see things the way \\ our minds have instructed our eyes to see. \\ Muhammad Yunus \\ Social entrepreneur and Nobel Laureate
}

\begin{abstract}
Innovation development is key to transforming a product-based economy into an innovative service economy by integrating users as co-creators in real-life environments. User co-creation and user involvement are key elements in living labs. Urban living labs add not only the urban component to the conceptual design, but also societal, political, and technological questions. Fields of analysis in urban research relate to socio-spatial environment, living together, and urban policies. The leading question of this article is: to what extent can urban living labs be used as an instrument to support these fields of investigation? Comparing three different approaches for urban living labs, ranging from socially-centred to more technology-centred, we offer a more nuanced understanding of urban living lab design in diverging research contexts. All three case studies manage to go beyond testing and improving new products, which is normally the aim of existing living labs, by embedding innovation in appropriate social, structural, and institutional frameworks, and targeting civil society involvement. The community benefits from this case study comparison because it contextualizes living labs as research methodology to be applied in future urban research projects.
\end{abstract}

\section{Introduction}

Living labs have become an established tool for testing and developing new products or services with users in real-life environments (see Leminen et al., 2012; Veeckman et al., 2013). They were also introduced into urban research agendas by the Finnish European Union Presidency in 2006. Since then, research programmes have been using living labs as a methodological tool to connect research to public and private stakeholders with citizens in order to co-create and co-design products and services to improve the quality of life in cities (Edwards-Schachter et al., 2012; Pascu \& Van Lieshout, 2009). Although projects and approaches to urban living labs differ widely, the benefits lie in user integration and the use of results to develop need-based products and services that can be implemented into the living en- vironments of citizens. As Schuurman (2015) points out, the key components of living labs are user involvement and user co-creation. Contrary to the predominately technology-centred living lab concepts, urban living labs add not only the urban component to the conceptual design, but also a range of topics including societal, political, and technological questions. As a result, a more nuanced understanding of living lab design in diverging research contexts is necessary to provide adequate frameworks in diverging fields of research.

This article extends the existing knowledge on living lab approaches by considering living labs as a tool to create a contextualized methodology within urban research. We introduce and use a typology to compare three different types and concepts of urban living labs from ongoing research projects by descriptive dimensions 


\title{
Contextuality and Co-Creation Matter: A Qualitative Case Study Comparison
}

\author{
Yvonne Franz, Karin Tausz, and Sarah-Kristin Thiel
}

operating at different levels. This qualitative case study comparison offers new and context-dependent insights into urban living lab approaches and the complexity of the term. Based on the research questions and disciplines of selected case studies, the objective of this article is to further contextualize them as a tool within research methodology. Finally, this article reflects on the question of how cities can trigger social innovation and redistribute and share the outcomes of successful co-creation in the wider urban society.

\section{Background}

The living lab concept originally emerged almost ten years ago during the European repositioning aimed at (again) becoming a competitive, innovation-based economy (Pascu \& Van Lieshout, 2009). According to the European Commission, four "P's" became the focus of collaboration: public-private-people-partnership (Schuurman, 2015). The starting point for living lab approaches is rooted in product-testing and has developed through the implementation of popular showcases at the Massachusetts Institute of Technology (MIT) in Boston or with the Urban Labs at the University of Chicago (Markopoulos \& Rauterberg, 2000; Schumacher \& Feurstein, 2007). The Philips Homelab or Fraunhofer InHaus are European examples, largely focusing on product-based technology laboratories (Schuurman, 2015), whereas examples from universities have the advantage of involving university staff and students as both active researchers and testers (Franz, 2015).

For a comprehensive literature overview on mostly technological living lab publications, see Følstad (2008) or Schuurman (2015). Both authors demonstrate the evolution of the living lab debate from a technologically-centred approach that focuses on innovation research. Emphasis lies in the innovationbased economy, where co-creation processes with users are implemented in real-life test environments (Pascu \& Van Lieshout, 2009; Mulder, 2012; Schumacher \& Feurstein, 2007). As Franz (2015) points out, "innovation" mainly refers to open innovation processes, including testing and validating a reactive integration of citizens, and developing and co-creating processes for an active integration of citizens (Pascu \& Van Lieshout, 2009). Although the starting point of co-creation can be traced back to precise scopes in architecture or participatory design projects (see Sanders \& Stappers, 2008), the definition of co-creation became fuzzy over time (see Schuurman, 2015; Winthereik et al., 2009; Ståhlbröst \& Bergvall-Kåreborn, 2008; Veeck- man, 2013). Reasons can be found in diverging outcomes that largely depend on the general methodological setup or actors and their diverging role of interest in being involved (see Juujärvi \& Pesso, 2013). In this article, we take co-creation to mean a collaborative new outcome between two or more groups of actors that include residents as a prerequisite. Co-creation is based on an explorative environment. Therefore, it is not possible to foresee whether a phase of co-creation can be achieved, as shown by many projects in urban research. Instead, we argue that living labs can be designed as an accompaniment to co-creation.

Existing literature suggests many definitions or approaches for living labs, and there are different cases in different countries. However, they mostly do not contextualize the methodology by taking into consideration discipline and research question and, hence, actors and adequate methods. This article offers an overview of innovation hubs and living labs currently being put into practice as part of Austrian urban research projects. The examples range from sociallycentred to more technology-centred approaches, addressing how and why civil society actors should be involved in these approaches. We focus on the comparison of three approaches, all of which investigate the potential of civil society involvement, taking into account its social, political, economic, and cultural heterogeneity. The first case deals with the involvement of residents in an impact analysis of local integration policies, whereas the second case implements and evaluates pervasive citizen participation. Both did not include co-creation as a mandatory element in the research design. The most advanced approach to cocreation can be found in the third case, which involves co-creators for urban mobility solutions, combining social and economic (technological) innovation. All three cases share the requirement to design context-depending living lab approaches. This need results in the main research question for this article, asking: What types and concepts have to be considered to design contextualized living lab approaches dealing with co-creation in the framework of urban research?

\section{Research Methodology}

Research project partners are often faced with a lack of continuity when it comes to the further development of research questions based on their findings after a project ends. The key question is how to foster innovation with more than a project-oriented approach, i.e. going "beyond projects" by cooperating in a living lab, building sustainable structures for cooperation with a long- 


\section{Contextuality and Co-Creation Matter: A Qualitative Case Study Comparison}

Yvonne Franz, Karin Tausz, and Sarah-Kristin Thiel

term perspective, and building confidence between all the involved stakeholders, which are essential for translating research results into action. We explore how this "going beyond" can be achieved by applying the living lab methodology. In order to both make our three cases studies comparable and provide a framework for future analysis, we developed a typology based on central factors of the living labs. Due to their complexity and the various contexts in which living labs can be applied, we argue that a case study analysis is the most appropriate method to provide a better understanding of living labs as a tool within research methodology. The unit of analysis here are the individual research projects. Data is gained through project documents as well as qualitative interviews with the project leaders and field notes by researchers participating in the selected living labs. The dimensions of the typology result from an iterative analysis process using document and content analyses. Table 1 summarizes the dimensions used in the typology.

As detailed in the previous section, the aims of technology and social-centered living labs differ widely, while the initial idea of co-creation persists (Franz, 2014). These aspects concern more the long-term objectives in a living methodology, but there are also short-term goals. Although they might be linked in some cases, both are relevant because they can greatly influence the methodology and course of a living lab. These differences in the aims of a living lab are the first dimension in our typology.
Stakeholders involved in living labs can be companies, non-profit organizations, special interest groups, universities, and municipalities. They all have their own motivations and agendas for becoming involved. Their level of involvement and motivation is also closely linked to the point at which they enter the living lab or project. Some stakeholders needed for the successful execution of the project (e.g., municipalities as official or legal entities) are relatively passive during the living lab, whereas other stakeholders take on an active role and pursue their own goals. This symbiotic coexistence allows the latter to be considered partners of researchers in the living lab.

With the emergence of socially-oriented approaches, the role of stakeholders and participants has shifted from an indirect to a direct factor in co-creation processes. In that context, the question arises of how cocreation is understood. Some scholars argue that cocreation has to have a novel outcome (e.g., a service or process), and it remains uncertain which stakeholders need to be involved - and to what extent - to enable that co-creation. Based on these considerations, the type and level of involvement by stakeholders form another dimension in our typology for comparing living lab models.

Technology-centred living labs are not typically designed to gain external approval; instead, they aim for efficiency. However, when embedded in a research context, the insights resulting from living labs need to be

Table 1. Typology used to compare selected living labs

\begin{tabular}{|c|c|c|}
\hline Objective & $\begin{array}{l}\text { - Short-term } \\
\text { - Long-term }\end{array}$ & What are the project's objectives during the living lab? \\
\hline Stakeholders & $\begin{array}{l}\text { - Interest \& motivation } \\
\text { - } \quad \text { Aims }\end{array}$ & Which stakeholders are involved and what is their motivation to take part? \\
\hline Involvement & $\begin{array}{l}\text { - Stakeholders } \\
\text { - Citizens }\end{array}$ & How is co-creation understood? \\
\hline
\end{tabular}

Transferability

To what extent can the results be generalized? 


\title{
Contextuality and Co-Creation Matter: A Qualitative Case Study Comparison
}

\author{
Yvonne Franz, Karin Tausz, and Sarah-Kristin Thiel
}

transferable. No one living lab is the same, nor are the cities in which they take place. Each lab has different living environments and different settings to be considered as contextual factors. Although the goal of a living lab is to make use of real-life complexities (Schuhmacher \& Feurstein, nd.), the transferability of the results needs to be ensured in order to be of value to the broader research community.

Given these dimensions and their various characteristics, it becomes apparent that there cannot be a "one size fits all" living lab concept, applied to every setting. Although living labs may be alike in one dimension, the projects in which they are carried out could have very diverse objectives and approaches. As a result, there is a clear need for contextualization.

\section{Case Studies: Living Labs in Practice}

In this section, a description of three research projects within the fields of urban research is offered. These portraits serve to provide concrete examples for different urban living lab concepts considering the context of wider framework conditions located in cities. Special attention is paid to the identified classifiers (see Table 1).

\section{Interethnic Coexistence in European Cities (ICEC)}

Within the JPI Urban Europe programme, the ICEC project focuses on interethnic coexistence in Amsterdam, Stockholm and Vienna. The main aim lies in the identification of effects on neighbourhood identity and co-responsibility through participation in local integration policies. These might include bottom-up initiatives or top-down policy measures, for instance, free preschool. Due to a lack of existing living lab concepts that focus on socio-spatial research questions, ICEC designed a socially-centred approach to implementing living labs by applying the concept of a "space of encounter". This means that the researcher accesses places where local residents already meet and interact with each other, for instance, community centres or public spaces. The "space of encounter" depends on the local conditions in each city, such as access to migrant groups and collaboration with local stakeholders that serve as "door-openers" to residents (Franz, 2015). As for the objectives, the ICEC urban living lab aims to gain knowledge at two levels: i) in methodological design as a short-term objective and ii) in policy analysis as a long-term objective, given that these results have the capacity to be considered and developed by politicians and the public sector after the project ends. As for the level of involvement, the ICEC urban living lab as a space of encounter is able to collaborate with stakeholders and engage with affected residents over a longer period, based on trust-building activities. As a result, openness to informal conversations and formalized semi-structured interviews with ethnically diverse residents seems likely compared to similar research designs that do not allow the long-term interaction between researchers and (non-)participants. This outcome is different to technologically-centred approaches that may also apply user-centric approaches in the users' social environment. However, the ICEC urban living lab clearly benefits from its localized character, ranging in form from a community room to a marketplace or neighbourhood garden. The methodological design did not include co-creation as a mandatory element. However, it allows the co-creation of more needs-based policies between researchers, local residents, and local stakeholders as a collaborative initiative beyond the initial project duration.

As a result, contextualization of the ICEC living lab refers to a spatial component, the space of encounter, as well as to a defined set of actors that require practice-based methods such as participatory observation resulting in qualitative interviews. As for interim results in the ICEC project, the analysis has identified a tendency across all social groups towards a low interdependency between participation in local activities and neighbourhood identity. With regard to co-creation, the ICEC living lab is recognizing a beneficial outcome of long-term interaction between local residents, stakeholders, and researchers. Over time, the understanding of local needs and adjusted policies has become more detailed and is currently being transferred into co-created measures supported by co-responsible residents, local (public) stakeholders, and the research institution.

\section{Building Pervasive Participation (b-Part)}

b-Part is another project embedded in the JPI Urban Europe funding stream. Its living lab is currently being implemented in the city of Turku, Finland, over a period of five months. In close cooperation with local authorities, the project explores the requirements, opportunities, and impacts of implementing pervasive citizen participation concepts in urban governance. In this context, a purpose-built mobile application serves as a vehicle for the research. Together with in-depth interviews with users, its data will serve to answer the project's research questions. The development of the prototype followed an iterative user-centred design process. 


\section{Contextuality and Co-Creation Matter: A Qualitative Case Study Comparison}

Yvonne Franz, Karin Tausz, and Sarah-Kristin Thiel

Gathering quantitative as well as qualitative data is essential for the project's success, making the short-term goal recruiting enough users for the platform and encourage sustainable participation. The evaluation and iterative improvement of the prototype form both the short and long-term goals of the b-Part living lab. Viewed from the technology approach for living labs, the mobile prototype is the product to be evaluated in an actual living environment and improved through resident-driven development.

The consortium of the b-Part project brings together three different research disciplines, which approach the research questions from various perspectives: human-computer interaction and research regarding social and political aspects. Through the involvement of these diverse disciplines, the approach used in the bPart living lab can be considered both technology and efficiency-centred, as well as a socially-centred.

Encouraging civic involvement is difficult for a variety of reasons, some of which are connected to trust. In order to show people that their input is valued, city officials have been involved in the project from early on. With them responding to input and also implementing suggestions, we hope to increase the public trust in authorities for both sustainable participation and future partnerships between these two stakeholders.

Rooted in the basic principles of democracy, the motivation of the municipality to be an active part in the bPart living lab can be explained by the necessity of citizens' involvement. By being actively involved, urban planners hope to get valuable feedback on existing ideas, but also novel suggestions from citizens. For both the overarching goal is to improve communication between citizens and governance.

The involvement of both citizens and governance is central to the b-Part living lab. By actively using the mobile application and providing feedback, both stakeholders are contributing to the co-creation process, which helps identify the requirements for civic engagement tools. While city officials are also partners on an operational level (i.e. by co-organising structures for the living lab), both stakeholders are not only users of a product (i.e. the prototype), but also directly (city officials and urban planners) and indirectly shaping (citizens) concepts for enhanced participation.

\section{Urban Mobility Labs (UML) - Research environments for future mobility}

The transport system is largely shaped and determined by users. A precondition for innovation in urban mobility is therefore socio-economic and exploratory research and the creation of socially innovative nodes and quarters. On the supply side, future mobility is no longer a carrier-only topic; numerous different industry sectors are involved, new players need new business and cooperation models, and public authorities need new models to achieve the transport policy goals. Urban mobility living labs show great potential in tackling the challenge of how future urban mobility can be organized, with the user at the centre. Starting at the beginning of 2015, eight project consortia throughout Austria began developing feasibility studies for living labs on specific topics, ranging from C-ITS (cooperative systems), influencing mobility behaviour, and the sharing economy, to cognitive and digital mapping. The objective is to overcome the pure technological focus through the cooperation of different actors and the involvement of citizens as co-creators, defining organizational structures and new alliances across the entire innovation chain. A prerequisite for breaking down institutional boundaries towards cross-solutions and close coordination is a long-term living lab framework enabling cooperation beyond single projects, with a planning perspective of four to seven years, not only to enable the incorporation of the findings made in the living lab into further research, but also into the implementation of solutions and future strategies. All of the feasibility studies will involve different kinds of actors to get them on board for the implementation of the living labs, though it differs depending on the specific topic:

- Cities benefit from involvement in projects at a very early stage by customized social and technological innovation, and they gain more value from strategic investments.

- Industry gains access to test users and data and can take into account the needs of cities and users at an early stage, developing new business models in cooperation with the partners of the living lab.

- Researchers/academics gain access to test users and test data, can demonstrate and test in real-life conditions, and can pursue long-term research with the partners in the living lab.

- Citizens change from consumers to valuable co-creators, not only for new services and products, but also for coordination processes as local experts for their mobility needs in the city. 


\section{Contextuality and Co-Creation Matter: A Qualitative Case Study Comparison}

Yvonne Franz, Karin Tausz, and Sarah-Kristin Thiel

Urban mobility labs are based on a common approach, but will differ in the specific organizational arrangements and methods of involving citizens. While appreciating that the labs will not offer a "one size fits all" solution, findings and insight concerning user involvement and the creation of cooperation structures will be transferable to other cities with similar challenges. Special attention is given to the redefinition of the public authorities' role: to reach transport policy goals, it is essential that they be a strong partner in the implementation rather than just the funder. This approach needs an appropriate mix of interventions along the whole innovation chain. Conclusions on an appropriate living lab structure for cooperation and testing in real-life environments deliver better feedback on the impact of funded projects aiming at establishing an innovation climate and reaching national and European goals for innovation in specific sectors. The implementation of two to three labs will be funded in 2016/2017.

\section{Conclusion}

The comparison of the three projects shows the scope of divergent approaches for urban living labs, covering such diverse questions as integration, participation, and mobility. This article contributes to a more nuanced understanding of "co-creation" that can be considered both a mandatory or a co-evolving element within living lab designs. Accompanying that, we emphasize the ability for long-term interaction between public and private actors, including citizens and researchers, as a core benefit in living labs, allowing cocreation beyond the initial research project.
As for the main research question on the creation of contextualized living lab approaches that allow co-creation in urban research, the comparative case study analysis in this article shows the dominant influence of the core interest of research. The research question is the main driver when it comes to selecting the actors involved in the process and determining their motivations, interests, and needs. The crucial element for contextualization is then to decide on the spatial setup of the actual living lab as well as to select more practicebased and engaging methods. Living labs have the capacity to support co-creation within urban research as long as openness to changes can be provided in the long term. In this respect, all three cases show a deficit in a truly co-created methodology, because the design, space, and actors involved in the living lab were chosen by the project teams. Co-created outcomes are expected to be achieved as long as interaction between researchers and living lab participants can be ensured. However, as long as the co-creation process is dependent on the duration of a research project, collaboration will be constrained to a set timeframe.

Moving beyond co-created outcomes - such as social innovation - requires a long-term commitment to the living lab remaining in place and to allowing enhanced collaboration between residents, public and private stakeholders, as well as researchers. In that respect, we conclude with a critical statement to not overestimate the potential of co-creation and social innovation while underestimating contextualizing factors such as space and time in living lab designs. 


\section{Contextuality and Co-Creation Matter: A Qualitative Case Study Comparison}

Yvonne Franz, Karin Tausz, and Sarah-Kristin Thiel

\section{About the Authors}

Yvonne Franz is a post-doctoral researcher at the Institute for Urban and Regional Research within the Austrian Academy of Sciences. She studied Economics and Geography at the Ludwig-Maximilians-Universität in Munich, the University of Cologne, and the University of Vienna, and she received her $\mathrm{PhD}$ on gentrification processes in New York City, Berlin, and Vienna in 2013. She is now involved in two JPI Urban Europe projects dealing with gentrification processes (Practices and Policies for Neighbourhood Improvement: Towards Gentrification 2.0) and interethnic coexistence (ICEC - Interethnic Coexistence in European Cities) that includes the urban living lab approach. She is a lecturer at University of Vienna and co-organizer of the Vienna Summer School in Urban Studies.

Karin Tausz is Head of Innovation \& E-Mobility at AustriaTech. She received a Master's degree in economics from the University of Vienna, Austria. Her experience includes policy consulting and innovation management for urban mobility, ITS and e-mobility, addressing public authorities, and companies. She was previously research coordinator at the Mobility Department of the applied science organisation AIT. She has been active for over 20 years in regional and urban development as a project manager, evaluator, and consultant with an emphasis on public participation, transport, and governance.

Sarah-Kristin Thiel is a Project Manager at the Telecommunications Research Centre Wien and is pursuing a $\mathrm{PhD}$ from the University of Salzburg. In her thesis, she investigates the influence of game-inspired elements in civic engagement platforms. She received a Master's degree in Media Informatics from LudwigMaximilians University in Munich, Germany. During her studies, she has gained experience in the automotive industry, human-machine interaction, and mobile development. Her research interests include (mobile) human-computer interaction, interaction design, and technology in society.

\section{Acknowledgements}

An earlier version of this paper was presented at the XXVI International Society for Professional Innovation Management (ISPIM) Conference - Shaping the Frontiers of Innovation Management, Budapest, Hungary, 14-17 June, 2015.

\section{References}

Allen, S., Bailetti, T., \& Tanev, S. 2009. Components of Co-creation. Open Source Business Resource, November 2009: 11-18. http://timreview.ca/article/301

Almirall, E., \& Wareham, J. 2011. Living Labs: Arbiters of Mid- and Ground-Level Innovation. Technology Analysis \& Strategic Management, 23(1): 87-102.

Bergvall-Kåreborn, B., \& Ståhlbröst, A. 2009. Living Lab: An Open and Citizen-Centric Approach for Innovation. International Journal of Innovation and Regional Development, 1(4): 356-370. http://dx.doi.org/10.1504/IJIRD.2009.022727

Edwards-Schachter, M. E., Matti, C. E., \& Alcántara, E. 2012. Fostering Quality of Life through Social Innovation: A Living Lab Methodology Study Case. Review of Policy Research, 29(6): 672-692. http://dx.doi.org/10.1111/j.1541-1338.2012.00588.x

Følstad, A. 2008. Towards a Living Lab for the Development of Online Community Services. The Electronic Journal for Virtual Organizations and Networks, 10: 47-58.

Følstad, A. 2008. Living Labs for Innovation and Development of Information and Communication Technology: A Literature Review. Electronic Journal of Virtual Organisations, 10: 99-131.

Franz, Y. 2014. Chances and Challenges for Social Urban Living Labs in Urban Research. In Conference Proceedings of Open Living Lab Days 2014: 105-114. Brussels: European Network of Living Labs (ENoLL).

Franz, Y. 2015. Designing Social Living Labs in Urban Research. info, 17(4): 53-66.

http://dx.doi.org/10.1108/info-01-2015-0008

Juujärvi, S., \& Pesso, K. 2013. Actor Roles in an Urban Living Lab: What Can We Learn from Suurpelto, Finland? Technology Innovation Management Review, 3(11): 22-27.

http://timreview.ca/article/742

Leminen, S., Westerlund, M., \& Nyström, A.- G. 2012. Living Labs as Open-Innovation Networks. Technology Innovation Management Review, 2(9): 6-11.

http://timreview.ca/article/602

Markopoulos, P., \& Rauterberg, G. W. M. 2000. Living Lab: A White Paper. In IPO Annual Progress Report, 35: 53-65.

Mulder, I. 2012. Living Labbing the Rotterdam Way: Co-Creation as an Enabler for Urban Innovation. Technology Innovation Management Review, 2(9): 39-43.

http://timreview.ca/article/607

Pascu, C. \& Van Lieshout, M. 2009. User-Led, Citizen Innovation at the Interface of Services. info, 11(6): 82-96.

http://dx.doi.org/10.1108/14636690910996731

Sanders, E. B.-N., \& Stappers, P. J. 2008. Co-Creation and the New Landscapes of Design. CoDesign, 4(1): 5-18.

Schumacher, J., \& Feurstein, K. 2007. Living Labs - The User as CoCreator. Results from Corelabs: Co-Creative Living Labs. 13th International Conference on Concurrent Enterprising (ICE). Sophia Antipolis, France.

Schuurman, D. 2015. Bridging the Gap between Open and User Innovation? Exploring the Value of Living Labs as a Means to Structure User Contribution and Manage Distributed Innovation. Dissertation at Ghent University and Vrije Universiteit Brussel VUB. 


\section{Contextuality and Co-Creation Matter: A Qualitative Case Study Comparison}

Yvonne Franz, Karin Tausz, and Sarah-Kristin Thiel

Tanev, S., Knudsen, M. P., Bisgaard, T., \& Thomsen, M. S. 2011. Innovation Policy Development and the Emergence of New Innovation Paradigms. Technology Innovation Management Review, 1(2): 14-19.

http://timreview.ca/article/496
Veeckman, C., Schuurman, D., Leminen, S., \& Westerlund, M. 2013. Linking Living Lab Characteristics and Their Outcomes: Towards a Conceptual Framework. Technology Innovation Management Review, 3(12): 6-15.

http://timreview.ca/article/748

Citation: Franz, Y., Tausz, K., \& Thiel, S.-K. 2015. Contextuality and Co-Creation Matter: A Qualitative Case Study Comparison of Living Labs

Concepts in Urban Research. Technology Innovation Management Review, 5(12): 48-55. http://timreview.ca/article/952

Keywords: urban living labs, co-creation, participation, social innovation, innovation ecosystem 